\title{
Novas bases para as políticas públicas de segurança no Brasil a partir das práticas do governo federal no período 2003-2011
}

\author{
Lígia Mori Madeira \\ Universidade Federal do Rio Grande do Sul (UFRGS) \\ Alexandre Ben Rodrigues \\ Universidade Federal do Rio Grande do Sul (UFRGS)
}

\begin{abstract}
A pesquisa investiga as novas bases para a formulação das políticas de segurança pública brasileira a partir da análise dos avanços recentes na área, enfocando o Programa Nacional de Segurança Pública com Cidadania (Pronasci). Desde o processo de redemocratização brasileira, os problemas sociais se exacerbaram, como os altos índices de criminalidade e violência em decorrência de um histórico processo de exclusão e desigualdade social das camadas mais baixas da população. A pesquisa busca explicitar as trajetórias da implementação de um novo paradigma no que tange à segurança pública. Assim, toma-se como modelo o processo de descentralização, que faz dos municípios atores-chave da gestão em segurança pública, atuando em cooperação com os outros entes federativos, como estados e União. Os resultados da pesquisa evidenciam o surgimento de um novo modelo de gestão da segurança pública no Brasil no período analisado, baseado no conceito, internacionalmente aceito, de segurança cidadã.
\end{abstract}

Palavras-chave: segurança pública; políticas públicas; violência; Pronasci.

Nuevas bases para políticas de seguridad pública en Brasil a partir de las prácticas del gobierno federal en el periodo 2003-2011

El estudio investiga las nuevas bases de formulación de las políticas de seguridad pública brasileña, a partir del análisis de los últimos avances en el ámbito de la política nacional, centrándose en lo Programa Nacional de Seguridad Publica con Ciudadanía (Pronasci). Con el proceso de democratización en Brasil, se agravan problemas como los altos índices de delincuencia y violencia como resultado de un proceso histórico de exclusión y la desigualdad social de las capas inferiores de la población. La investigación trata de explicar la trayectoria de la implementación de un nuevo paradigma en materia de seguridad pública, siguiendo el modelo de un proceso de descentralización que hace de los municipios actores clave en la gestión de la seguridad pública, en colaboración con otras entidades federales,

DOI: http://dx.doi.org/10.1590/0034-76121702

(cc) BY-NC

Artigo recebido em 25 ago. 2013 e aceito em 9 set. 2014. 
tales como estados y la Unión. El resultado de la investigación muestra el surgimiento de un nuevo modelo de gestión de la seguridad pública en Brasil en el período analizado, basado en el concepto, aceptado internacionalmente, la seguridad ciudadana.

Palabras clave: seguridad pública; políticas públicas; violencia; Pronasci.

New bases for the public security policies in Brazil from the practices of the federal government in the period of 2003-2011

The research investigates the new bases of formulation of the Brazilian public security policies from the analysis of recent advances in the area, focusing on the national program of public security with citizenship (Programa Nacional de Segurança Pública com Cidadania - Pronasci. Since the redemocratization process in Brazil, the social problems have increased like the high rates of crime and violence as a result of a historical process of exclusion and social inequality of the lowest classes of the population. The research seeks to explain the trajectories of the implementation of a new paradigm regarding the public security. Therefore, it is considered as a model the process of decentralization that makes municipalities key-players of the management of the public security, working in cooperation with other federal entities, such as states and the Union. The research results show the emergence of a new model of public security management in Brazil in the period analyzed, based on the concept, internationally accepted, of citizen security.

KeYwords: public security; public policies; violence; Pronasci.

\section{Introdução}

Desde a década de 1980, o tema da segurança tem ocupado uma efetiva centralidade na agenda pública brasileira. A Constituição de 1988 organizou as demandas sociais do período e, somada aos já crescentes índices de violência no país, colocou de vez a segurança pública como uma preocupação presente nas três esferas federativas. Contudo, ao contrário das instituições que na transição democrática se transformaram e se aperfeiçoaram, as polícias (até então a referência primordial das políticas de segurança) não foram objeto de reformas substantivas que rompessem com os legados institucionais e a cultura prévia. Pode-se dizer que a polícia, como instituição pública, não foi adequada pela Constituição ao novo momento democrático (Soares, 2003).

O problema da segurança pública tornou-se ainda mais premente em razão das altas taxas de criminalidade e violência, da exclusão social ainda elevada e da penetração do crime nas instituições públicas. Em função disso, analisar o itinerário das políticas do setor sob o enfoque dos marcos institucionais que sustentam tais políticas é um exercício importante e necessário. Se a segurança, como uma subárea das políticas públicas sociais, passou quase incólume às reformas constitucionais dos anos 1980, recebendo apenas no ano 2000, durante o governo Fernando Henrique Cardoso, a sua primeira grande diretriz nacional (Plano Nacional de Segurança Pública), torna-se necessário observar sua evolução recente à luz das diretrizes que, entre os anos de 2003 e 2011, lhe deram uma nova conformação institucional. O foco deste trabalho é justamente compreender o papel da União em matéria de segurança pública 
como indutora de políticas públicas nos últimos 10 anos, por meio da reprodução de um modelo de sistemas de políticas públicas que, à luz de outros setores como a saúde e a assistência social, vêm construindo experiências de coordenação de políticas, em movimentos de formulação, pelo ente federal, de programas que serão implementados por estados e municípios.

Nesse sentido, busca-se observar de forma mais acurada a experiência do Programa Nacional de Segurança Pública com Cidadania (Pronasci), analisando suas características como política pública, bem como os significados de sua implementação tanto para o governo federal, que passa a ter um papel central inovador, quanto para os estados, atores tradicionais nessa área. Outro ponto fundamental para se compreender as mudanças na segurança pública brasileira diz respeito à municipalização e à descentralização das políticas públicas, consolidando o papel do município como cogestor da segurança pública. Tal processo está baseado em uma série de justificativas, como a customização das políticas públicas, que permite a restituição de visibilidade e do valor pessoal por apropriações individualizadas e singulares, estabelecendo as famílias como alvo prioritário de políticas dirigidas a jovens. Além disso, baseia-se na produção de protagonismo, com a atribuição de determinadas responsabilidades pela decisão e pela condução dos processos às populações locais. Outra característica é a circunscrição da problemática e a focalização territorial, responsáveis pela motivação de atores locais, pela mobilização social e pela disseminação de novo padrão de expectativas.

Em termos metodológicos, o artigo é uma tentativa de sistematizar resultados de investigações que tiveram o processo de implementação do Pronasci como foco, especialmente no estado do Rio Grande do Sul. Foram realizadas análises legislativas e documentais, observação participante, entrevistas com gestores, articuladores, coordenadores de projetos e público-alvo da política, especialmente em territórios vulneráveis, como os de implantação dos Territórios de Paz.

O artigo está estruturado em três seções, além da introdução e da conclusão. A primeira delas aborda os paradigmas e os modelos históricos que contribuíram na formação das variadas formas de atuação do Estado brasileiro na área de segurança pública; a segunda seção detém-se nas políticas públicas propriamente ditas sob o viés da prevenção da violência, sendo esse um fator novo na história da segurança pública brasileira; e, por fim, a terceira seção dedica-se mais exclusivamente ao Pronasci.

\section{Estado e segurança pública}

Antes de lançar luzes sobre o período mais atual das políticas públicas de segurança no Brasil, convém trazer alguns elementos para compreender as raízes do modelo de gestão pública brasileira e conectá-lo a modelos ou paradigmas vigentes na área da segurança pública. Assim, podemos tomar como base três fases ou paradigmas que caracterizam o Estado brasileiro, na ótica das políticas de segurança pública: o paradigma da segurança nacional, vigente no período da ditadura militar; o paradigma da segurança pública a partir da Constituição Federal de 1988; e o paradigma da segurança cidadã, que tem início por volta do ano 2000 (Freire, 2009). 
Em termos mais amplos, o modelo de Estado implementado após o golpe militar em 1964 pode ser caracterizado, no âmbito econômico, pelo ideário reformista e desenvolvimentista, que passou a se definir a partir da concentração de riqueza que visava a aprofundar o projeto de industrialização e a abertura da economia ao capital externo. Na medida em que o Brasil assumiu responsabilidades no exterior, começou a nascer a noção de objetivos nacionais, para orientar essa atuação. Essa doutrina penetrou entre os militares brasileiros, uma vez que o contexto ditatorial lhes possibilitou a prerrogativa de se colocarem acima da Constituição e das leis do país. Essa defesa do status quo social, implicitamente, obstruía a modernização das estruturas sociais. Começa a se firmar a doutrina da segurança nacional, na qual a estagnação econômica é vista como um mal menor em face das ameaças de instabilidade interna (Furtado, 1970). Esse movimento institucional do período militar afetou também as políticas sociais e configurou uma atuação baseada na violência e no combate à "subversão", o que formatou muito do padrão de atuação das polícias. Além do mais, nesse momento já havia a inserção brasileira na perspectiva do disciplinamento - com legislações criminalizantes da vadiagem, da prostituição, do jogo (Madeira, 2009).

A principal orientação em matéria de políticas de segurança no período foi, portanto, a da Doutrina de Segurança Nacional e Desenvolvimento, formulada pela Escola Superior de Guerra (ESG). Essa doutrina foi moldada em torno do conceito de segurança nacional, definido então como a habilidade de um Estado garantir, em determinada época, a obtenção e a manutenção de seus objetivos nacionais, apesar dos antagonismos ou das pressões existentes ou potenciais. Dessa forma, o conceito de defesa nacional estava intimamente associado à defesa do Estado, e esse princípio foi expresso na primeira Constituição promulgada pelo regime militar, em 1967. Em suma, o paradigma de segurança nacional caracterizou-se pela prioridade dada, inicialmente, ao inimigo externo, materializado no combate ao comunismo; e, posteriormente, ao inimigo interno, correspondente a qualquer indivíduo percebido como contrário à ordem vigente. A ameaça à segurança aqui é vista como tudo aquilo que atenta contra o Estado e contra os interesses nacionais, intimamente associados aos interesses daqueles que estão no poder (Freire, 2009).

No entanto, ao longo da década de 1980, a organização do Estado foi mudando. Toda a reflexão realizada no período levava aos temas do republicanismo e da democracia, utilizando-se de conceitos como accountability, transparência, participação política, equidade e justiça - questões praticamente ausentes nas políticas públicas em décadas anteriores —, culminando na promulgação da Constituição Federal de 1988. A esse período que se inicia em 1988 podemos atribuir conceitualmente, contudo, outro paradigma, fundamentado no próprio art. 144 da Constituição, que estabelece a segurança pública como a defesa da incolumidade das pessoas e do patrimônio público e privado por meio de suas várias instituições ou órgãos de polícia.

A nova Constituição, promulgada em 5 de outubro de 1988, consagrou um conjunto de mudanças institucionais: alargamento do elenco dos direitos (civis, sociais e políticos); desbloqueio da comunicação entre sociedade civil e Estado; reconhecimento das liberdades civis e públicas; abolição das organizações paramilitares ou organismos paralelos à segurança públi- 
ca. Além disso, o racismo e a tortura converteram-se em crimes inafiançáveis e imprescritíveis; conferiu-se autonomia ao Ministério Público; e consagrou-se a assistência judiciária aos desprovidos de recursos para constituição de defensoria própria. Em síntese, a nova Constituição procurou munir a sociedade de instrumentos de defesa contra o arbítrio do poder de Estado. Por outro lado, não alterou significativamente os dispositivos legais impostos pelos governos militares para organizar as polícias, que na época eram entendidas como forças de segurança do Estado, e não uma instituição de interesse público. Essas opções tomadas na Constituinte de 1988 contribuíram para que a estrutura de funcionamento montada pelo regime militar no final da década de 1960 se mantivesse quase inalterada (Adorno, 1996). Pode-se afirmar que esse paradigma inova em relação ao paradigma anterior, ao destacar que a segurança pública é dever do Estado e direito e responsabilidade de todos. No entanto, na lista de responsáveis pela segurança pública, ela destaca apenas as instituições policiais federais e estaduais, não citando o papel de outras instituições governamentais na prevenção à violência, ou mesmo a importância da atuação dos municípios e da comunidade como um todo (Freire, 2009).

Apesar dos avanços democráticos do período, não se obteve a efetiva instauração do estado democrático de direito. Persistiram violações de direitos humanos, calcadas em uma cultura do uso de práticas violentas manifestadas tanto no comportamento de grupos da sociedade civil quanto no dos agentes da ordem pública. Nas últimas décadas do século XX, a modernização da segurança pública ficou restrita, quase que exclusivamente, à expansão física através da construção de novas instalações e de aumento do contingente policial; de renovação da frota de veículos e do sistema de comunicações; e de profissionalização de quadros mediante aperfeiçoamento em cursos especializados. Porém essas medidas pouco têm contribuído para compatibilizar o funcionamento das forças policiais com as exigências do estado democrático de direito (Adorno, 1996).

Em termos de políticas públicas de segurança, há pouco o que se destacar nesse período no Brasil. Pode-se dizer que, durante a década de 1990, o que se verificou foi o fortalecimento de um Estado penal e repressivo, voltado ao controle penal daqueles que continuavam sem ter acesso a direitos sociais. Esse fato pode ser constatado pelo crescimento da população carcerária, pelo debate e uso das Forças Armadas no controle à criminalidade de narcotraficantes de drogas em favelas, e toda a criminalização societária que isso proporciona (Madeira, 2009). Em suma, a atuação estatal continuava voltada a medidas criminalizadoras e ostensivas, mais do que propriamente a ações de proteção social.

Há ainda mais um aspecto a ser ressaltado, o qual é fundamental para compreender o novo momento da segurança como política pública: a descentralização das políticas para estados e municípios. A responsabilidade fundamental sobre a segurança pública, nesse conceito, passa a ser prioritariamente dos estados, por serem estes os responsáveis pela gestão das polícias civil e militar. Esse arranjo, que preservava a militarização da segurança pública, dotou os estados de autonomia relativa na condução da política de segurança, mas, ao mesmo tempo, dificultou a implementação de diretrizes mínimas de uma política nacional de segurança, o 
que poderia trazer prejuízo para a prevenção e o controle da violência e da criminalidade, pois a manifestação desses fenômenos não respeita as fronteiras estaduais.

No final da década de 1990, foi criada a Secretaria de Planejamento de Ações Nacionais de Segurança Pública, transformada em seguida em Secretaria Nacional de Segurança Pública (Senasp). No decreto de sua criação, foi estabelecido que cabe à Senasp assessorar o ministro de Estado da Justiça na definição e implementação da política nacional de segurança pública, e, em todo o território nacional, acompanhar as atividades dos órgãos responsáveis pela segurança pública. A Senasp passou então a atuar buscando a articulação entre as unidades federativas, visando à estruturação do Sistema Único de Segurança Pública (Susp). Inspirado no sistema único desenvolvido no âmbito das políticas de saúde (SUS), o Susp visava à articulação das ações federais, estaduais e municipais na área de segurança pública, buscando aperfeiçoar o planejamento e a troca de informações para uma atuação qualificada dos entes federados na área. O Susp não busca a unificação - pois reconhece a autonomia das instituições que compõem o sistema —, mas sim a integração, otimizando resultados (Freire, 2009).

Se ao longo da história brasileira as políticas de segurança pública eram vistas como políticas de repressão, calcadas na atuação de órgãos de controle e busca da diminuição da criminalidade, a partir do ano 2000 abriu-se espaço para uma tendência em se conceber a política de segurança como cidadã, tendo como foco não mais a exclusiva repressão da violência, mas sim a prevenção e a promoção de convivência social segura e pacífica, com respeito aos direitos humanos. Chegamos assim ao paradigma da segurança cidadã, que incorpora avanços iniciados na década de 1990, como a reorganização institucional do governo federal, mas amplia em termos conceituais o entendimento sobre que modelo de política de segurança pública pode trazer resultados mais efetivos ao bem-estar da população.

O arcabouço de sustentação do conceito de segurança cidadã pode ser encontrado na produção intelectual de organismos internacionais como a Organização das Nações Unidas (ONU) e sua agência para área do desenvolvimento social, o Programa das Nações Unidas para o Desenvolvimento (Pnud). Através da construção do conceito de desenvolvimento humano, expresso no Índice de Desenvolvimento Humano (IDH) e nos Objetivos de Desenvolvimento do Milênio (ODM), busca-se induzir os países a adotarem medidas e ações governamentais em torno da proteção dos direitos humanos aliada à modernização do Estado para elaborar políticas públicas mais inclusivas e integradas, visando promover desenvolvimento econômico sem deixar de lado a redução das desigualdades sociais. Essa aproximação do governo brasileiro com os organismos internacionais através dos acordos de cooperação para implementação de políticas públicas forneceu muitos subsídios teóricos para a elaboração das políticas de segurança pública.

As perspectivas abertas pelos organismos internacionais já influenciavam nos anos 1990 outras iniciativas na América Latina, como na Colômbia, onde ações de prevenção à violência foram implementadas com sucesso na cidade de Bogotá, dando ao conceito de segurança cidadã uma experiência prática na gestão pública. O êxito do governo colombiano ajudou a difundir essa nova proposta para outros países da região, em especial o Brasil (Martin e Ceballos, 2004). 
Em termos de definição desse conceito, podemos dizer que ele parte da natureza multicausal da violência e, nesse sentido, defende a atuação tanto no espectro do controle como na esfera da prevenção, por meio de políticas públicas integradas no âmbito local. Dessa forma, uma política pública de segurança cidadã envolve várias dimensões, reconhecendo a multicausalidade da violência e a heterogeneidade de suas manifestações. Uma intervenção baseada no conceito de segurança cidadã tem necessariamente de envolver as várias instituições públicas e a sociedade civil, na implementação de ações planejadas a partir dos problemas identificados como prioritários para a diminuição dos índices de violência e delinquência em um território, englobando iniciativas em diversas áreas, tais como educação, saúde, lazer, esporte, cultura, cidadania, dentre outras (Freire, 2009).

De acordo com a definição dada pelo governo federal e materializada no Projeto de Lei no ${ }^{-11.530 / 2007}$, no art. 30, a segurança cidadã

(...) consiste na situação política e social de segurança integral e cultura da paz em que as pessoas têm, legal e efetivamente, garantido o gozo pleno de seus direitos fundamentais, por meio de mecanismos institucionais eficientes e eficazes, capazes de prever, prevenir, planejar, solucionar pacificamente os conflitos e controlar as ameaças, as violências e coerções ilegítimas.

Em meio a todo esse debate, a partir do ano 2000, com o lançamento do Plano Nacional de Segurança Pública, os municípios passam a ser vistos como espaços de produção e promoção de políticas de segurança pública, especialmente cidadã, que enfatizam a "importância da inserção dos municípios ou do poder local na promoção de políticas de prevenção do crime e da violência" (Mesquita Neto, 2006:6).

No entanto faltava um arcabouço normativo para definir a relação da União com estados e municípios. Reconhecendo a gravidade do problema da segurança pública no Brasil, o governo federal, por meio do Ministério da Justiça, iniciou, em 2003, uma nova etapa na história da segurança pública brasileira. Tendo como foco principal de ação a implantação do Susp, a Senasp consolidou-se como o órgão central no planejamento e na execução das ações de segurança pública em todo o Brasil.

Os gestores das organizações de segurança pública, em todas as unidades da federação, passaram a se reunir regularmente para planejar e executar ações por meio dos Gabinetes de Gestão Integrada (GGI). A gestão das ações de segurança pública no país passou a contar com o apoio de uma série histórica de informações estatísticas coletadas pelo Sistema Nacional de Estatísticas de Segurança Pública e Justiça Criminal (SINESPJC).

Com a implantação da Matriz Curricular Nacional, passou-se a padronizar os processos de capacitação dos profissionais de segurança pública em todos os estados brasileiros, tendo como um dos principais eixos a valorização dos direitos humanos e a promoção da cidadania. De forma sistêmica, a Rede Nacional de Educação a Distância passou a garantir um processo de formação contínua para todos os profissionais de segurança pública. No final de 2006, mais de 27 mil profissionais já estavam matriculados e haviam concluído algum ou mais de um curso de qualificação. Reforçando esse processo de padronização e qualificação nacional dos 
equipamentos e procedimentos na área de segurança pública, a Força Nacional de Segurança Pública já formou mais de 7 mil policiais de todo o Brasil. Em uma situação de emergência, a Força Nacional constitui-se em uma resposta eficaz para apoiar as forças policiais das unidades federadas.

A Senasp estipulou que a implantação do Susp seria realizada pela dedicação às ações convergentes dispostas em sete eixos estratégicos: gestão do conhecimento; reorganização institucional; formação e valorização profissional; prevenção; estruturação da perícia; controle externo e participação social; e programas de redução da violência. Sob essas diretrizes, foi construído em 2003 o Plano Nacional de Segurança Pública, que tinha por objetivo construir um consenso com os governadores em torno do próprio plano, de suas virtudes e sua viabilidade, demonstrando os benefícios que proporcionaria para o conjunto do país e para cada estado, em particular, se fossem feitos os esforços necessários, em moldes cooperativos, suprapartidários, republicanos, para que se superassem as resistências corporativas, as limitações materiais, as dificuldades operacionais e de gestão, e se implementassem as medidas propostas.

Os pontos fundamentais do acordo a celebrar seriam a normatização do Susp e a desconstitucionalização das polícias. Aos governos estaduais e federal caberia instalar Gabinetes de Gestão Integrada da Segurança Pública, um em cada estado, que funcionaria como braço operacional do Susp e começaria a trabalhar com base no entendimento político, antes mesmo da normatização que o institucionalizaria. O GGI seria um fórum executivo que reuniria as polícias de todas as instâncias e, mediante convite, as demais instituições da justiça criminal. As decisões seriam tomadas apenas por consenso, para que se eliminasse o principal óbice para a cooperação interinstitucional: a disputa pelo comando (Soares, 2007).

Nos anos que se seguiram, os GGIs começaram a operar imediatamente e, nos anos seguintes, nos raros estados em que não foram esvaziados pelo boicote político, renderam frutos e demonstraram-se formatos promissores. Cumpriria ao governo federal, por sua vez, não contingenciar os recursos do Fundo Nacional de Segurança Pública, em 2003, e aumentálo consideravelmente nos anos subsequentes — razão pela qual foi iniciada negociação com o Banco Mundial e o BID, tencionando um aporte a juros subsidiados de US 3,5 bilhões, por sete anos. O Fundo Nacional de Segurança seria aceito pelos credores como a contrapartida do governo federal. Também competiria ao governo federal enviar ao Congresso Nacional a emenda constitucional da desconstitucionalização das polícias e, como matéria infraconstitucional, a normatização do Sistema Único de Segurança Pública. Uma vez endossados os termos do acordo com os 27 governadores, o presidente os convocaria para a celebração solene do Pacto pela Paz, reiterando politicamente o compromisso comum com a implantação do Plano Nacional de Segurança Pública (Soares, 2007).

O presidente reviu sua adesão ao plano e desistiu de prosseguir no caminho previsto, porque teria percebido - na interlocução com a instância que, à época, se denominava "núcleo duro do governo" - que fazê-lo implicaria assumir o protagonismo maior da reforma institucional da segurança pública no país, ou seja, assumir a responsabilidade pela segurança perante a opinião pública. Isso, de certa forma, segundo o autor, o exporia a riscos políticos, 
pois a responsabilidade por cada problema, em cada esquina, de cada cidade, lhe seria imputada. O desgaste seria inevitável, uma vez que os efeitos práticos de uma reorganização institucional só se fariam sentir a longo prazo (Soares, 2007).

Outro aspecto muito importante desse movimento foi a inserção dos municípios nas políticas públicas de segurança, o que reflete, por um lado, os modelos internacionais, tanto americanos quanto europeus, em que há tanto polícias nacionais como municipais, mas especialmente as tendências europeias de descentralização de políticas de segurança; por outro lado, o processo de descentralização das políticas públicas e sociais de saúde, habitação, educação e assistência, que é largamente debatido pelas ciências sociais brasileiras, também parece ter servido de exemplo.

Somada a tudo isso, a constatação de que o problema do crime e da violência tem uma dimensão urbana, atingindo áreas e grupos específicos, que tratados localmente podem suscitar uma maior compreensão e a adoção de ações de prevenção, justificou a incorporação dos municípios nessa temática (Pinheiro, 1998). As políticas municipais de segurança cidadã permitem:

a) O desenvolvimento de políticas adequadas à realidade local, sensíveis às expectativas da população;

b) O estabelecimento de parcerias entre agências governamentais e entre estas e organizações da sociedade;

c) A operação de instrumentos democráticos de controle, monitoramento e avaliação das políticas públicas (Soares, 2005 apud Mesquita Neto, 2006:7).

Em termos de organização estatal, as mudanças no tratamento do tema da segurança pública são em muito resultantes de ações indutivas do governo federal nas esferas estadual e municipal. Apesar das rupturas, podem-se estabelecer continuidades entre os planos de segurança pública propostos pelos governos federais desde o início da década de 2000, que assinalam

(...) um deslocamento significativo no que diz respeito ao tratamento do assunto até então - a segurança pública adentra a agenda de discussões para assumir um lugar central nos compromissos da União, rompendo com uma postura inercial que deixava os problemas da segurança restritos aos Estados e suas polícias. (Azevedo e Fagundes, 2007:91).

Os planos nacionais de segurança pública destacam-se pela ênfase nas ações preventivas, pelo apoio à qualificação profissional, a busca de integração e estímulo ao uso das penas alternativas, do policiamento comunitário, do respeito e garantia de direitos humanos, do controle de armas. Além disso, somada aos planos, inicia-se a implementação de um projeto de segurança pública para o Brasil no qual se destacam a normatização do Susp, a instalação de gabinetes de gestão integrada nos estados, além de uma série de ações pensadas e articuladas a partir da Senasp do Ministério da Justiça (Barbosa et al., 2008). 


\section{A atualidade das políticas de segurança pública com enfoque na prevenção da violência}

Como parte da atuação coordenadora/indutora do Poder Executivo federal desta última década em matéria de segurança pública, cabe citar o Pronasci, que se destinou à "prevenção, controle e repressão da criminalidade, atuando em suas raízes socioculturais, articulando ações de segurança pública e política social" (Lei ํo 11.530/2007).

Em 20 de agosto de 2007, o governo federal, por meio do Ministério da Justiça, lançou o Pronasci através da Lei no 11.530, comprometendo-se a investir R \$ 6,707 bilhões, até o fim de 2012, em um conjunto de 94 ações que envolveram 19 ministérios, em intervenções articuladas com estados e municípios. Através do Pronasci, os entes federados passaram a ter a possibilidade de desenvolver ações de prevenção à violência adaptadas à sua realidade local e com o aporte de recursos da União para isso:

(...) São eles: a integração intergovernamental (entre a União, Estados e Municípios; entre os poderes Legislativo, Executivo e Judiciário); a gestão intersetorial de projetos (com a participação em cada ente federado de diversos ministérios ou secretarias); o recurso às abordagens interdisciplinares (aqui parte-se do pressuposto de que a criminalidade e a insegurança são fenômenos complexos e que, portanto, demandam abordagens múltiplas e diversificadas); a participação comunitária (que busca integrar os organismos da sociedade civil nos esforços de planejamento e execução de programas preventivos); a inserção local (considerando que as dinâmicas criminais e conflitivas só podem ser compreendidas e abordadas a partir do contexto local); a prevenção situacional (que implica no redesenho do espaço urbano e na melhoria dos serviços de infraestrutura); a prevenção social (baseada no entendimento de que as causas e as dinâmicas criminais estão associadas a fenômenos sociais abrangentes: educação, saúde, cultura, economia etc.). (Barbosa et al., 2008:391-392)

Entre os eixos do Pronasci estavam o desenvolvimento dos seguintes objetivos e programas:

1) Modernização institucional, através da modernização de instituições de segurança pública e do sistema prisional;

2) Valorização profissional: de profissionais de segurança pública e agentes penitenciários;

3) Enfrentamento à corrupção policial e ao crime organizado;

4) Território de Paz;

5) Integração do jovem e da família;

6) Segurança e convivência.

Do ponto de vista dos princípios matriciais, o Pronasci reiterava o Plano Nacional de Segurança Pública do primeiro mandato do presidente Lula, o qual, por sua vez, incorporava, 
sistematizava e explicitava o que já estava, embrionária ou tacitamente, presente no Plano Nacional do governo Fernando Henrique Cardoso (Soares, 2007). Aliado a isso, o Pronasci consolidava em ações e poder orçamentário parte significativa das diretrizes que no início da década anunciavam uma virada de perspectiva nas políticas públicas sobre segurança, qual seja, investir na dimensão preventiva da violência em diálogo com as principais reivindicações por atenção aos direitos humanos na prática do Estado de promover a segurança pública.

Contudo, não houve somente avanços com o Pronasci. O fato de o programa ter sido desenhado de forma muito robusta, com diversas ações, acabou restringindo seu poder transformador, pois, em vez de unidade sistêmica, fruto de diagnóstico que identifica prioridades e revela as interconexões entre os tópicos contemplados pelo plano, tem-se a listagem de propostas que na prática da gestão geraram fragmentação do produto final. Também o envolvimento de um número excessivo de ministérios estabeleceu um arranjo não muito realista, sabendo-se quão atomizada é nossa máquina pública e quão burocráticos e departamentalizados são os mecanismos de gestão. Além disso, as reformas institucionais das polícias não são tematizadas pelo programa. Assim, o status quo policial e, mais amplamente, o quadro fragmentário das instituições da segurança pública acabam sendo assimilados (Soares, 2007). Desse modo, naturaliza-se o legado da ditadura, chancelando-se a transição incompleta como a transição possível. O Pronasci, apesar das transformações que gerou como política social e inclusiva, deixou intocado um aspecto crucial para a adoção de um novo modelo de segurança pública: as reformas institucionais.

A implementação do Pronasci expôs também uma série de fragilidades da gestão pública no Brasil. Ao descentralizar a gestão e a execução do programa, o Ministério da Justiça apostou na eficiência dos estados e municípios para colocar essa política pública em funcionamento. Contudo, em muitos dos casos, os entes federados jamais tinham executado políticas de prevenção à violência e nem possuíam estrutura de gestão (conhecimento, recursos humanos, contrapartida financeira, entre outros) para essa realização. O resultado prévio desses quatro anos de execução é ainda de uma relação custo-benefício muito desfavorável, afora, evidentemente, algumas experiências muito bem-sucedidas com o Pronasci em alguns estados e municípios do Brasil.

Não pretendemos aqui analisar a efetividade do programa, mas sim suas proposições, por preconizar um atrelamento entre a discussão penal e o âmbito social, uma vez que existe uma série de outros estudos que se propõem a essa tarefa sob diversos prismas. Alguns estudos analisam a relação dos três níveis de governo na implementação do Pronasci, mostrando a dificuldade da divisão de competências (Battibugli, 2012); o papel da União como formuladora de políticas de segurança, a qual tem como demanda a necessidade de avanços na democratização - no sentido de maior participação nas discussões — das ações de segurança pública (Carvalho e Silva, 2011); a execução das ações do Pronasci nos municípios (Madeira, 2012; Cardoso, 2011); ou ainda a análise com recorte de gênero, tentando compreender as especificidades do público-alvo do programa (Bezerra, 2010).

Em suma, pode-se afirmar que, em termos de competência, o Pronasci foi um programa federal executado pela União, através de órgãos e entidades federais, com a adesão volun- 
tária de estados, Distrito Federal e municípios. A forma de execução do programa previu a realização de convênios, acordos, ajustes entre órgãos e entidades da administração pública, entidades de direito público e organizações da sociedade civil de interesse público (Oscips). A gestão foi realizada por ministérios, órgãos e entidades participantes, sob a coordenação do Ministério da Justiça.

Entre as ações executadas pelo Pronasci, estiveram:

I — promoção dos direitos humanos, considerando as questões de gênero, étnicas, raciais, geracionais, de orientação sexual e de diversidade cultural;

II — criação e fortalecimento de redes sociais e comunitárias;

III — promoção da segurança e da convivência pacífica;

IV — modernização das instituições de segurança pública e do sistema prisional;

V - valorização dos profissionais de segurança pública e dos agentes penitenciários;

VI - participação do jovem e do adolescente em situação de risco social ou em conflito com a lei, do egresso do sistema prisional e família;

VII — promoção e intensificação de uma cultura de paz, de apoio ao desarmamento e de combate sistemático aos preconceitos;

VIII — ressocialização dos indivíduos que cumprem penas privativas de liberdade e egressos do sistema prisional, mediante a implementação de projetos educativos e profissionalizantes;

IX — intensificação e ampliação das medidas de enfrentamento do crime organizado e da corrupção policial;

$\mathrm{X}$ - garantia do acesso à justiça, especialmente nos territórios vulneráveis;

XI — garantia, por meio de medidas de urbanização, da recuperação dos espaços públicos; e

XII — observância dos princípios e diretrizes dos sistemas de gestão descentralizados e partici-

pativos das políticas sociais e resoluções dos conselhos de políticas sociais e de defesa de direitos afetos ao Pronasci (Brasil, 2007b).

O programa teve como foco principal de atuação: I. foco etário: população juvenil de 15 a 29 anos; II. foco social: jovens e adolescentes, em situação de risco social, e egressos do sistema prisional e famílias expostas à violência urbana; e III. foco territorial: regiões metropolitanas e aglomerados urbanos que apresentem altos índices de homicídios e de crimes violentos. O Pronasci foi implementado com mais peso em 11 regiões metropolitanas, sendo elas: Belém, Belo Horizonte, Brasília, Curitiba, Maceió, Porto Alegre, Recife, Rio de Janeiro, Salvador, São Paulo e Vitória.

O Pronasci propôs uma mudança paradigmática do conceito de segurança do Estado para segurança cidadã. Para tanto, buscou compreender a segurança pública em um sentido mais amplo, constituindo a base através da qual o sujeito se mobiliza em defesa da saúde, da educação, da igualdade de oportunidades e da juventude para a consolidação de um novo modo de vida. Para tanto, o Pronasci articulou políticas de segurança com ações sociais, priorizando a prevenção da violência no combate a suas causas, sem se esquecer de agir também sobre os efeitos que ela inevitavelmente gera. Entre os principais eixos do Pronasci desta- 
caram-se a valorização dos profissionais de segurança pública; a reestruturação do sistema penitenciário; o combate à corrupção policial; e o envolvimento da comunidade na prevenção da violência. Para o desenvolvimento do programa, o governo federal investiu R \$ 6,7 bilhões até o fim de 2012.

A execução do Pronasci deu-se por meio de mobilizações policiais e comunitárias. A articulação entre os representantes da sociedade civil e as diferentes forças de segurança polícias civil e militar, corpo de bombeiros, guarda municipal, secretaria de segurança pública - foi realizada pelos Gabinetes de Gestão Integrada Municipais (GGIM). O Pronasci foi coordenado por uma secretaria-executiva em nível federal e regionalmente dirigido por uma equipe que atuou junto aos GGIM e tratou da implementação das ações nos municípios. Toda essa complexidade na execução do programa se explica pela necessidade de formar uma rede articulada para garantir que tanto as ações policiais como os projetos sociais caminhem lado a lado.

Para caracterizar os chamados programas locais, em contraposição com as ações estruturais que dizem respeito basicamente à reestruturação das polícias civil e militar através da modernização institucional e logística, deve-se destacar o Território de Paz. Foi organizado em um bairro com altos índices de violência de um município conveniado com o Pronasci, no qual se buscou uma reorganização do espaço urbano e dos equipamentos públicos, além da implementação de um Conselho e da Polícia Comunitária e uma série de programas sociais, como o Mulheres da Paz (voltado à formação de lideranças femininas que funcionarão como mediadoras e encaminhadoras de jovens para os programas disponíveis no local) e o Protejo. O Território de Paz, portanto, visou a tornar uma comunidade hoje assolada pela violência e pela criminalidade em uma referência de espaço urbano seguro e de promoção da justiça com igualdade social.

Embora o Pronasci tenha tido uma ampla variedade de ações, cabe destacar aqui aquelas mais diretamente voltadas à juventude, que no âmbito desse programa foi caracterizada por jovens de 15 a 24 anos à beira da criminalidade, que se encontravam ou já haviam estado em conflito com a lei; presos ou egressos do sistema prisional; e ainda os reservistas, passíveis de serem atraídos pelo crime organizado em função do aprendizado em manejo de armas adquirido durante o serviço militar. Uma série de parcerias do Ministério da Justiça com os ministérios do Esporte, da Cultura, da Educação, entre outros, permitiu uma integração dos programas sociais já existentes com o público-alvo atendido pelo Pronasci.

Uma das principais ações do Pronasci voltada ao público juvenil foi o Projeto de Proteção dos Jovens em Território Vulnerável (Protejo), que prestou assistência, por meio de programas de formação e inclusão social, a jovens adolescentes expostos à violência doméstica ou urbana ou que vivam nas ruas. O trabalho teve duração de um ano, prorrogável por mais um, e teve como foco a formação da cidadania desses jovens por meio de atividades culturais, esportivas e educacionais que visassem a resgatar sua autoestima e permitir que eles disseminassem uma cultura de paz em suas comunidades. Para desenvolver esse trabalho, o Protejo deu atenção ao jovem nas suas dimensões individual, familiar, comunitária e social, proporcionando-lhe uma formação integral e facilitando sua inclusão social. 
Ao longo do ano de duração do Protejo, suas atividades foram divididas em dois ciclos, um com 440 horas e outro com 360 horas. A maior parte dessa carga horária foi contemplada com oficinas que abordavam temas como violência, autoestima, sexualidades, paternidade responsável, meio ambiente, direitos humanos, cidadania, protagonismo juvenil, drogas e redução de danos, com a possibilidade de o poder público local inovar na escolha de temas, buscando responder às demandas e às características da juventude que atende. Além das oficinas, os jovens também tiveram a oportunidade do desenvolvimento de práticas cidadãs, com a produção de projetos comunitários visando à sua inserção responsável na comunidade em que vivem, contribuindo para o desenvolvimento local.

Durante os dois primeiros meses de participação nas atividades do Protejo, o jovem não estava obrigado a matricular-se na escola. Havia o entendimento do Ministério da Justiça de que esta condicionante, em um primeiro momento, acabaria funcionando como fator de evasão, já que muitos jovens abandonaram a escola por diversos fatores, e sua reinclusão deveria ser promovida de forma gradual. Mas, ao longo da sua participação no Protejo, o jovem deveria construir o seu percurso social formativo, que foi possibilitado pela oferta, por parte do poder público, de uma série de oportunidades para o jovem envolver-se com o ensino formal, inicialmente através do acesso aos Telecentros para a inclusão digital, os Pontos de Leitura e Pontos de Cultura, chegando aos programas mais abrangentes, como o Brasil Alfabetizado, o Proeja e o Projovem, além de cursos preparatórios para o Enem e o ProUni.

Ao articular ações de segurança pública e medidas de promoção da cidadania, o Pronasci estruturou uma série de ações capazes de auxiliar no combate à exclusão social dos jovens, contribuindo para a democratização do nosso sistema de justiça e da construção de uma relação mais harmônica entre o Estado e a sociedade civil. No entanto, como era previsto, o prazo legal do programa encerrou-se, e um novo desafio foi colocado para o Estado brasileiro. Algumas pesquisas (Madeira, 2012) evidenciaram que de maneira geral o Pronasci e a metodologia de implantação dos Territórios de Paz tiveram uma avaliação positiva por parte do público-alvo, gerando inclusive uma mudança na visão dessa população sobre a vida e os estigmas de serem pertencentes a bairro com altos índices de violência. Percebeu-se também que a população diretamente atendida pelo Pronasci sempre desejou a manutenção das ações que formam o Território de Paz, demonstrando apoio e convicção sobre sua eficácia, comprovada também pela redução do número de homicídios da população jovem. No entanto, é fundamental o surgimento de novas pesquisas que possam ajudar a compreender os efeitos dessas políticas.

\section{O Pronasci e sua relação com estados e municípios}

Cabe ainda mencionar alguns aspectos sobre as relações federativas que caracterizaram o Pronasci, no que diz respeito à participação de estados e municípios, uma vez que também aqui houve muita disparidade em relação à adesão ao programa, a qual era voluntária. 
De imediato, foi possível observar que os estados alinhados politicamente com o governo federal apresentaram projetos na linha do Pronasci e se organizaram para executar ações da mesma natureza. Foi o caso do Rio de Janeiro, cujo governo estadual optou por implementar não só as ações de repressão qualificada e modernização das polícias civil e militar (esta uma prerrogativa constitucional dos governos estaduais), mas também as ações de prevenção à violência com destaque para os projetos Mulheres da Paz e Protejo. O estado do Rio de Janeiro foi eleito como uma das prioridades do Pronasci pelo governo federal ainda em 2008 e desenvolveu a partir daí as Unidades de Polícia Pacificadora (UPP), seguindo o modelo dos Territórios de Paz do Pronasci, mas com um viés mais voltado à presença efetiva das polícias militares nas bases instaladas. No outro extremo, tivemos o exemplo do Estado de Minas Gerais, que desde o lançamento do Pronasci nunca tratou o programa como prioridade, optando por investir em ações próprias, como o programa Fica Vivo, voltado à redução dos homicídios no estado.

Foi possível perceber ainda casos híbridos, em que o Pronasci foi lançado durante a gestão de um governo ideologicamente oposto ao governo federal, tendo até as eleições de 2010 uma postura e, após esse período, com a eleição do candidato do Partido dos Trabalhadores (PT), mudado de ênfase. É o caso do Rio Grande do Sul, que durante o governo Yeda Crusius (PSDB) poucas ações do Pronasci se prestou a executar e, após a eleição de Tarso Genro (PT), se chegou a criar uma versão regional do Pronasci, batizado de RS na Paz, que procurou aproveitar melhor os recursos disponíveis e acrescentar novas ações aos Territórios de Paz, inclusive com recursos orçamentários próprios, e investir no policiamento comunitário.

No âmbito interno aos municípios foi possível verificar também a disputa constante entre perspectivas repressivas e preventivas, com aquelas muitas vezes ganhando a batalha na hora de definir prioridades e ações. Ou seja, as visões tradicionais da segurança pública como um campo de repressão nas mãos das instituições policiais muitas vezes eram reproduzidas mesmo nos espaços em que as ações inovadoras apresentavam mais força (Madeira, 2012).

No entanto, mais do que as disputas conceituais, o grande desafio sempre foi o de articular a gestão das ações, garantindo os fluxos e principalmente os prazos propostos. Por se tratar de um programa muito amplo e que envolvia um grande número de ministérios, somado à diversidade de realidades de preparação técnica e gerencial entre os municípios, o Pronasci teve dificuldades de se apresentar como um programa coeso e com uma finalidade clara. Em 2010, quando se fechavam dois anos de execução do Pronasci, um relatório do Tribunal de Contas da União (TCU) já fazia apontamentos nesse sentido.

O resultado dessa diversidade foi a criação de uma disparidade na transferência dos recursos financeiros, uma vez que os municípios mais preparados e com uma melhor estrutura gerencial e administrativa conseguiam cumprir os prazos para o envio de projetos, ao passo que outros não obtinham o mesmo sucesso. O grande problema desse fenômeno é que alguns dos municípios com mais dificuldades administrativas são também os mais carentes de recursos, mantendo-se assim um círculo vicioso.

Do ponto de vista da execução, um dos problemas encontrados no compartilhamento de ações do Pronasci foi a dificuldade das partes de promover avaliações e acompanhamento 
dos resultados do programa. Apesar de o contrato celebrado em 2009 entre a Fundação Getulio Vargas e o Ministério da Justiça ter permitido o desenvolvimento do Sistema de Monitoramento, Avaliação e Desenvolvimento Institucional do Pronasci, denominado Simap, o investimento realizado mostrou-se inócuo. Em primeiro lugar, o sistema desenvolvido apresentava, recorrentemente, problemas técnicos, o que o tornava de difícil acesso e consulta pelos gestores, tanto federais como estaduais e municipais. Em segundo lugar, o próprio Ministério da Justiça decidiu abandonar a proposta ao se deparar com as dificuldades apresentadas, não oferecendo outra solução para o monitoramento integrado do Pronasci.

O episódio do Simap foi bastante emblemático porque revelou uma faceta dramática da administração pública brasileira: a dificuldade de se acompanhar e monitorar os investimentos realizados em políticas públicas, permitindo posteriores avaliações de impactos e resultados. O fracasso dessa ferramenta contribuiu para que os estados e municípios pouco se detivessem em também monitorar os resultados que estavam obtendo com o programa.

Em suma, esses são os aspectos mais destacáveis dessa recente experiência de materialização do paradigma da segurança cidadã. Longe de querer esgotar o tema, buscou-se oferecer uma trilha para a compreensão dos esforços mais atuais da União e dos entes federados em prol das políticas públicas de segurança.

\section{Conclusão}

A análise histórica da última década evidencia uma mudança paradigmática no contexto das políticas públicas de segurança no Brasil. Não obstante, as mudanças havidas não deixam de guardar profundas ligações com o itinerário histórico do país ao longo dos séculos XIX e XX no que diz respeito à atuação das instituições do espectro criminal, em especial as polícias, e com as deficiências da gestão pública no quesito eficiência e efetividade. A formulação de políticas públicas de segurança não pode prescindir de uma acurada avaliação histórica dos modelos em voga e das trajetórias e dos resultados das diversas experiências que configuram o que hoje está posto para atender à demanda da população brasileira por mais segurança, justiça e proteção social.

Ao longo do período analisado, percebeu-se uma série de iniciativas estatais para dar conta do complexo problema da segurança pública, sendo a principal delas o Pronasci. Pensado como política pública voltada à redução de violência, teve como características a federalização e a descentralização, sendo uma política federal implementada por estados e municípios pela seleção de zonas ou bairros considerados vulneráveis e a execução de um conjunto de medidas e programas para redução de índices de criminalidade e melhora de indicadores sociais. O programa baseou-se no paradigma de segurança cidadã, que conjuga ações de repressão qualificada e prevenção à violência.

No entanto, depois de desenhados os projetos, o processo de divulgação e execução do programa nos diferentes municípios contou com dificuldades que vão desde o problema da falta de capacitação da burocracia brasileira, os entraves de direito administrativo, até a busca 
isolada por verbas para videomonitoramento, sem o interesse no cumprimento dos requisitos básicos para o recebimento de verbas pelo programa, que são a instauração dos gabinetes de gestão integrada e a implementação das ações de prevenção à violência. Outra grande dificuldade, atinente a grande parte das políticas públicas brasileiras, especialmente as da área da segurança, diz respeito à falta de monitoramento e avaliação das ações, ao levantamento de indicadores sociais e à medição de resultados e impactos.

Embora tenha havido todo esse esforço, na gestão das políticas públicas de segurança persiste a tensão entre visões punitivistas e cidadãs. E, apesar da constituição de um modelo híbrido, o Estado ainda se mostra frágil na condução das políticas para além das necessidades imediatistas de se apresentarem resultados às demandas da população, fazendo com que as políticas públicas não se consolidem como alternativas democráticas para a transformação das condições de vida da população brasileira.

Atualmente, concluído o período da execução do Pronasci como determinava a Lei n⿳o 11.530/2007, abriu-se um novo espaço, por enquanto vazio, em termos de um programa nacional estruturante para a segurança pública no Brasil. Isso porque o Ministério da Justiça manteve algumas das ações do programa, financiadas através de editais abertos a praticamente todos os estados e municípios, no âmbito do Susp; por outro lado, relegou esses projetos a uma condição de pouca visibilidade e articulação. Sem o poder de mobilização social (e até mesmo midiática) do Pronasci e com a diminuição dos recursos financeiros, que agora são disputados pelos entes federados, a política nacional de segurança perde seu poder agregador. É bem verdade que não existem estudos que corroborem de maneira objetiva a efetividade das ações do Pronasci. Contudo, uma política pública dessa magnitude só tem sucesso se implementada com uma projeção de longo prazo, buscando resultados e impactos que não estejam atrelados ao calendário eleitoral.

\section{Referências}

ABRUCIO, Luis Fernando. O impacto do modelo gerencial na administração pública: um breve estudo sobre a experiência internacional recente. Cadernos Enap, n. 10, 1997.

ADORNO, Sergio. A gestão urbana do medo e da insegurança: violência, crime e justiça penal na sociedade brasileira contemporânea. Tese (livre-docência) — Universidade de São Paulo, São Paulo, 1996.

AZEVEDO, Rodrigo G.; FAGUNDES, Andréia. A municipalização da segurança pública no Brasil: pressupostos teóricos e critérios para a implementação de políticas públicas de segurança. Revista de Estudos Criminais, n. 26, p. 89-106, 2007.

BARBOSA, Antonio R. et al. Reflexões sobre a municipalização da segurança a partir do diagnóstico de segurança pública do município de São Gonçalo (Rio de Janeiro). Civitas, v. 8, n. 3, p. 386-408, set./dez. 2008. 
BATTIBUGLI, Thaís. As iniciativas federais e as influências na política pública de segurança paulista. Revista Estudos de Política, v. 1, n. 2, p. 50-73, 2012.

BEZERRA, Cláudia M. Protagonismo feminino na prevenção da violência: o projeto Mulheres da Paz no estado do Rio de Janeiro. In: FAZENDO GÊNERO: DIÁSPORAS, DIVERSIDADES E DESLOCAMENTOS, 9., 2010, Florianópolis. Anais... Florianópolis: UFSC, 2010.

BRASIL. Lei n. 11.530, de 24 de outubro de 2007. Institui o Programa Nacional de Segurança Pública com Cidadania — Pronasci, e dá outras providências. Brasília, 2007b.

BRASIL. Ministério da Justiça. Relatório de atividades — Implantação do Sistema Único de Segurança Pública. Brasília: Senasp, 2007a.

CARDOSO, Mônica G. Política pública na área de segurança e cidadania: percepção dos moradores de Itapuã (DF) sobre o Pronasci. Monografia (especialização em Legislativo e políticas públicas) - Centro de Formação, Treinamento e Aperfeiçoamento, Câmara dos Deputados, Câmara dos Deputados, Brasília, 2011.

CARVALHO, Vilobaldo A.; SILVA, Maria R. F. Política de segurança pública no Brasil: avanços, limites e desafios. Katálysis, v. 14, n. 1, p. 59-67, jan./jun. 2011.

CERQUEIRA, Daniel; LOBÃO, Waldir. Criminalidade: social versus polícia. Ipea, Texto para discussão, n. 958, 2003.

DURANTE, Marcelo O.; ZAVATARO, Bruno. Limites e desafios da evolução da gestão em segurança pública no Brasil: a importância do uso de indicadores de avaliação de desempenho. São Paulo em Perspectiva, v. 21, n. 1, p. 76-91, jan./jun. 2007.

FREIRE, Moema D. Paradigmas da segurança no Brasil: da ditadura aos nossos dias. Revista Aurora, v. 3, n. 5, p. 49-58, dez. 2009.

FURTADO, Celso. Brasil: tempos modernos. Rio de Janeiro: Paz e Terra, 1970.

MADEIRA, Lígia M. A implementação do Pronasci na Região Metropolitana de Porto Alegre: um estudo sobre o processo e a efetividade da federalização das políticas públicas de segurança pública. Relatório de Pesquisa referente ao Edital 003/2009 ARD, Fundação de Amparo à Pesquisa no Rio Grande do Sul — FAPERGS. Porto Alegre, 2012.

MADEIRA, Lígia M. Mudanças no sistema de Justiça Criminal brasileiro nas duas últimas décadas: rumo a um Estado penal? Monografia (graduação em direito) — Faculdade de Direito, Pontifícia Universidade Católica do Rio Grande do Sul, Porto Alegre, 2009.

MARTIN, Gerard; CEBALLOS, Miguel. Bogotá: anatomia de uma transformação política de segurança cidadã (1995-2003). Bogotá: Pontifícia Universidade Javeriana, 2004.

MESQUITA NETO, Paulo de. Fazendo e medindo progresso em segurança pública. Praia Vermelha, n. 14-15, p. 184-197, 2006.

PINHEIRO, Paulo S. São Paulo sem medo: um diagnóstico da violência urbana. Rio de Janeiro: Garamond, 1998. 
RAUTER, Cristina. Criminologia e subjetividade no Brasil. Rio de Janeiro: Revan; ICC, 2003.

SOARES, Luiz E. A Política Nacional de Segurança Pública: histórico, dilemas e perspectivas. Estudos Avançados, v. 21, n. 61, p.77-97, 2007.

SOARES, Luiz E. Novas políticas de segurança pública. Estudos Avançados, v. 17, n. 47, p. 75-96, 2003.

ZAFFARONI, Eugenio R.; BATISTA, Nilo. Direito Penal brasileiro - I. Rio de Janeiro: Revan, 2006.

ZAFFARONI, Eugenio R.; PIERANGELI, José H. Manual de direito penal brasileiro: parte geral. São Paulo: RT, 1999.

Lígia Mori Madeira é professora do Departamento e do Programa de Pós-Graduação em Ciência Política da Universidade Federal do Rio Grande do Sul (UFRGS) e pesquisadora do Grupo de Pesquisa Violência e Cidadania (GPVC). E-mail: ligiamorimadeira@gmail.com.

Alexandre Ben Rodrigues é doutorando em ciência política no Programa de Pós-Graduação em Ciência Política da Universidade Federal do Rio Grande do Sul (UFRGS). E-mail: alexbenrodrigues@yahoo. com.br. 